pp. 91 - 100, April 2020

\title{
Effect of Liquid Media Composition on $\alpha$-Glucosidase Inhibitory Activity from Aspergillus elegans SweF9
}

\author{
Hani Mulyani, RiznaTriana Dewi, Euis Filailla, and Nina Artanti
}

Research Center for Chemistry - Indonesian Institute of Sciences, Kawasan PUSPITEK, Serpong, Tangerang Selatan, Banten 15314, Indonesia

*Corresponding author : hmulyani@yahoo.com

\begin{tabular}{|c|c|}
\hline$A R T I C L E$ INFO & Abstract \\
\hline $\begin{array}{l}\text { Revised date : } 24 \text { February } 2020 \\
\text { Accepted date: } 26 \text { February } 2020\end{array}$ & $\begin{array}{l}\text { The aim of this study is to determine the effect of liquid media composition on the } \\
\text { inhibitory activity of } \alpha \text {-glucosidase from endophytic fungus Aspergillus elegans } \\
\text { SweF9 isolated from seaweed (Macroalgae euchema). Fermentation was carried } \\
\text { out in three types of liquid media, namely: potato dextrose broth (PDB), potato } \\
\text { malt peptone (PMP), and Czapek-dox broth (CDB), which was incubated for } 10 \\
\text { days at room temperature with static conditions. Ethyl acetate were used to extract } \\
\text { active metabolites from fungal biomass and filtrate from each media. Antidiabetic } \\
\text { activity was measured based on inhibition of enzyme } \alpha \text {-glucosidase. The results } \\
\text { showed that filtrate extract of } A \text {. elegans SweF9 which was cultured on the media } \\
\text { PDB showed the highest inhibitor activity to the } \alpha \text {-glucosidase enzyme with an } \\
\text { IC } 50 \text { value of } 1.74 \mu \mathrm{g} / \mathrm{mL} \text {. Based on these results, the PDB media is an } \\
\text { appropriate medium for culturing } A \text {. elegans SweF9 to produces secondary } \\
\text { metabolites that can be used as a new source of antidiabetic agents. }\end{array}$ \\
\hline \multicolumn{2}{|l|}{$\begin{array}{l}\text { Available online at : } \\
\text { https://doi.org/10.14203/jkti.v21i2.426 }\end{array}$} \\
\hline \multicolumn{2}{|l|}{ Keywords: } \\
\hline $\begin{array}{l}\alpha \text {-glucosidase inhibitor, Aspergillus } \\
\text { elegans SweF9, endophytic fungus }\end{array}$ & $\begin{array}{l}\text { (C) } 2020 \text { Indonesian Journal of Applied Chemistry. This is an open access article under the } \\
\text { CC BY-NC-SA license (https://creativecommons.org/licenses/by-nc-sa/4.0/). }\end{array}$ \\
\hline
\end{tabular}

\section{INTRODUCTION}

The number of people with diabetes mellitus (DM) is increasing rapidly every year throughout the world including Indonesia. The last estimation from the International Diabetes
Federation (IDF) were 382 million people in the world living with DM in 2013. Based on basic health research (Riskesdas) in 2013, people with $\mathrm{DM}$ in Indonesia reached $6.8 \%$ and impaired 
glucose tolerance ( TGT) in urban areas reaches $29.9 \%$ [1].

Postprandial hyperglycemia plays an important role in the development of type $2 \mathrm{DM}$ and its complications. Therefore patients with type $2 \mathrm{DM}$ have to face therapy throughout their lives to control hyperglycemia and prevent complications. The tendency of the increasing number of people with type $2 \mathrm{DM}$ has become a medical concern of the world which seriously encourages various efforts to examine new therapeutic agents [2].

The $\alpha$-glucosidase is an enzyme that plays a role in the conversion of carbohydrates to glucose. The digestive process of carbohydrates includes the release of pancreatic enzymes into the intestine which will digest carbohydrates into oligosaccharides. The resulting oligosaccharides will be converted into glucose by the $\alpha$ glucosidase which released by the cell which is then finally absorbed by the body. By inhibiting the action of the $\alpha$-glucosidase, glucose levels in the blood can be maintained within normal limits [3].

Some drugs currently used clinically are acarbose and miglitol which inhibit glycosidases such as $\alpha$-glucosidase and $\alpha$-amylase, but some hypoglycemic agents have limitations, which cause side effects and increase diabetes complications. The main side effects of $\alpha$ glucosidase inhibitors in the gastrointestinal tract include bloating, nausea and diarrhea. Natural oral $\alpha$-glucosidase inhibitors derived from natural ingredients can be used as a therapeutic approach to treat postprandial hyperglycemia because they are thought to have low side effects and prices are more affordable than synthetic drugs [4]. Therefore we need research and development of new $\alpha$-glucosidase inhibitors from natural sources. With the uniqueness of its ecosystem, marine biota and marine microorganisms (endophytic microbes) have proven to have a lot of potential as a source of raw materials for the development of new medicines and cosmetics with unique molecular structures and new pharmacological mechanisms [5].

Indonesia has abundant natural resources, such as plants, animals, and microorganisms that can produce bioactive compounds as a source of new drug discoveries. One of them is Aspergillus fungi which is a type of fungi commonly found in soil but can also be isolated (from marine biota). The Aspergillus genus includes more than 185 species and is well known for the production of organic acids, statins, and extracellular enzymes that produce secondary metabolites of active compounds as drugs [6]. Aspergillus shows strong activity inhibits the action of the $\alpha$ glucosidase and free radical DPPH [7]. However, the factors that can influence inhibitor activity are not yet known clearly. Based on this matter, the aim of this study is to determine the effect of liquid media composition on the production of active metabolites and the inhibitory activity of $\alpha$-glucosidase from the endophytic fungus Aspergillus elegans SweF9 which is cultured in three liquid media, namely: potato dextrose broth (PDB), potato malt peptone (PMP), and Czapek-dox broth(CDB).

\section{EXPERIMENTAL}

\subsection{Materials}

\subsubsection{Microorganism}

A. elegans was isolated from marine biota/seaweed (Macroalgae euchema) [8] from Pameungpeuk Garut, West Java, which is a collection of Research Center for Chemistry, Indonesian Institute of Sciences (LIPI).

\subsubsection{Chemicals}

PDB, extra Malt extract, Czapek-dox broth, Pepton, and PDA were obtained from Difco, $\mathrm{NaNO}_{3}, \quad \mathrm{~K}_{2} \mathrm{HPO}_{4}, \quad \mathrm{MgSO}_{4} .7 \mathrm{H}_{2} \mathrm{O}, \mathrm{KCl}$, and $\mathrm{FeSO}_{4} .7 \mathrm{H}_{2} \mathrm{O}$, dimethyl sulfoxide oxidase (DMSO) were obtained from Merck. Saccharomyces cerevisiae and $p$-nitrophenyl $\alpha$ 92 |"Effect of Liquid Media Composition ...": Hani Mulyani, et.al. 
D-glucopyranoside ( $p$ NPG) were obtained from Wako Pure Chemical Industries Ltd.

\subsection{Methods}

\subsubsection{Media and Fermentation Process}

Isolated A. elegans SweF9 was inoculated in three types of liquid media, (PDB), (PMP), and (CDB). The nutritional composition of the media used is:

1. PDB : PDB $2.4 \%$

2. PMP : $2.4 \%$ PDB added $1.0 \%$ malt extract, and $0.1 \%$ peptone)

3. CDB: $3 \%$ sucrose, $0.2 \% \mathrm{NaNO}_{3}, 0.1 \%$ $\mathrm{K}_{2} \mathrm{HPO}_{4}, 0.05 \mathrm{MgSO}_{4} .7 \mathrm{H}_{2} \mathrm{O}, 0.05 \% \mathrm{KCl}$, $0.001 \% \quad \mathrm{FeSO}_{4} .7 \mathrm{H}_{2} \mathrm{O}$, and $0.5 \%$ yeast extract.

Each of the sterilized media $(50 \mathrm{~mL})$ was inoculated with $A$. elegans SweF9 which had previously been planted in PDA media for 7 days at $30^{\circ} \mathrm{C}$. Then, all of the media were incubated for 10 days at room temperature under static conditions. After the incubation period is completed, biomass and filtrate are separated and each one is extracted with ethyl acetate, and dried with a rotary evaporator. The dried extract obtained was used to the analysis of $\alpha$ glucosidase inhibitory activity.

\subsection{2. $\alpha$-Glucosidase inhibitory assay}

The enzyme inhibition activity for $\alpha$ glucosidase was assessed according to the methods reported by Kim et al [9], with minor modifications. The reaction mixture contained $250 \mu \mathrm{L}$ of $5 \mu \mathrm{mM} \quad p$-nitorpehenyl $\alpha$-Dglucopyranoside ( $p$ NPG), $495 \mu \mathrm{L}$ of $100 \mathrm{mM}$ phosphate buffer ( $\mathrm{pH}$ 7.0) adding to flask contain $5 \mu \mathrm{L}$ of sample dissolved in DMSO at various concentrations ( 5 to $50 \mu \mathrm{g} / \mathrm{mL}$ ). The reaction mixture was pre-incubated for $5 \mathrm{~min}$ at $37^{\circ} \mathrm{C}$, the reaction was start by adding $250 \mu \mathrm{L} \alpha$ -
Glucosidase (0.065 Unit/mL) (EC 3.2.1.20 from Wako Pure Chemical Industry) incubation was continued for $15 \mathrm{~min}$. The reaction stopped by adding $1 \mathrm{~mL}$ of $0.1 \mathrm{M} \mathrm{Na}_{2} \mathrm{CO}_{3}$. Activity of $\alpha-$ glucosidase was determined by measuring release of $p$-nitrophenol at $400 \mathrm{~nm}$. Individual blanks for test samples were prepared to correct background absorbance where the enzyme was replaced with $250 \mu \mathrm{L}$ of phosphate buffer.

The inhibition activity presentation is measured by using the equation:

$\%$ Inhibition $=\underline{(\mathrm{C}-\mathrm{S}) \times 100}$

C

$\mathrm{C}=$ blank absorbance (DMSO)

$\mathrm{S}=$ sample absorbance (difference between

absorbers with and without enzymes).

\subsubsection{Analysis of fungal metabolite by HPLC}

The content of the active compound in the ethyl acetat was analyzed using with HPLC (Water, USA), UV detector at a wavelength $(\chi)$ of $300 \mathrm{~nm}$, and reserved - phase C18 column (Type UG 120, $5 \mu \mathrm{m}$, size 4,6 mm I.D. x 250 $\mathrm{mm})$. An isocratic using water : methanol

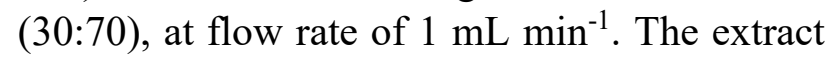
was dissolved in methanol at a concentration 1 $\mathrm{mg} / \mathrm{mL} ; 10 \mu \mathrm{L}$ were injected [10].

\section{RESULT AND DISCUSSION}

\subsection{Selection of optimum media for fungus $\boldsymbol{A}$. elegans SWeF9}

In the fermentation process, the choice of media composition will greatly affect the metabolites secreted by fungi into the media [11]. Based on this, the present study aimed to investigate the effect of media composition on $\alpha$ glucosidase inhibitory activity. Aspergillus the genus that has the most species and strains found in the marine, terrestrial and plant environments 
and is known to have bioactive compounds as antioxidants [12]. Endophytic fungus A. elegans SweF9 originated from marine biota is shown in Figure 1.
In this study, three liquid media which were used to culture A. elegans, PDB, PMP, and CDB with a fermentation time of 10 days under static conditions is shown in Figure 2.

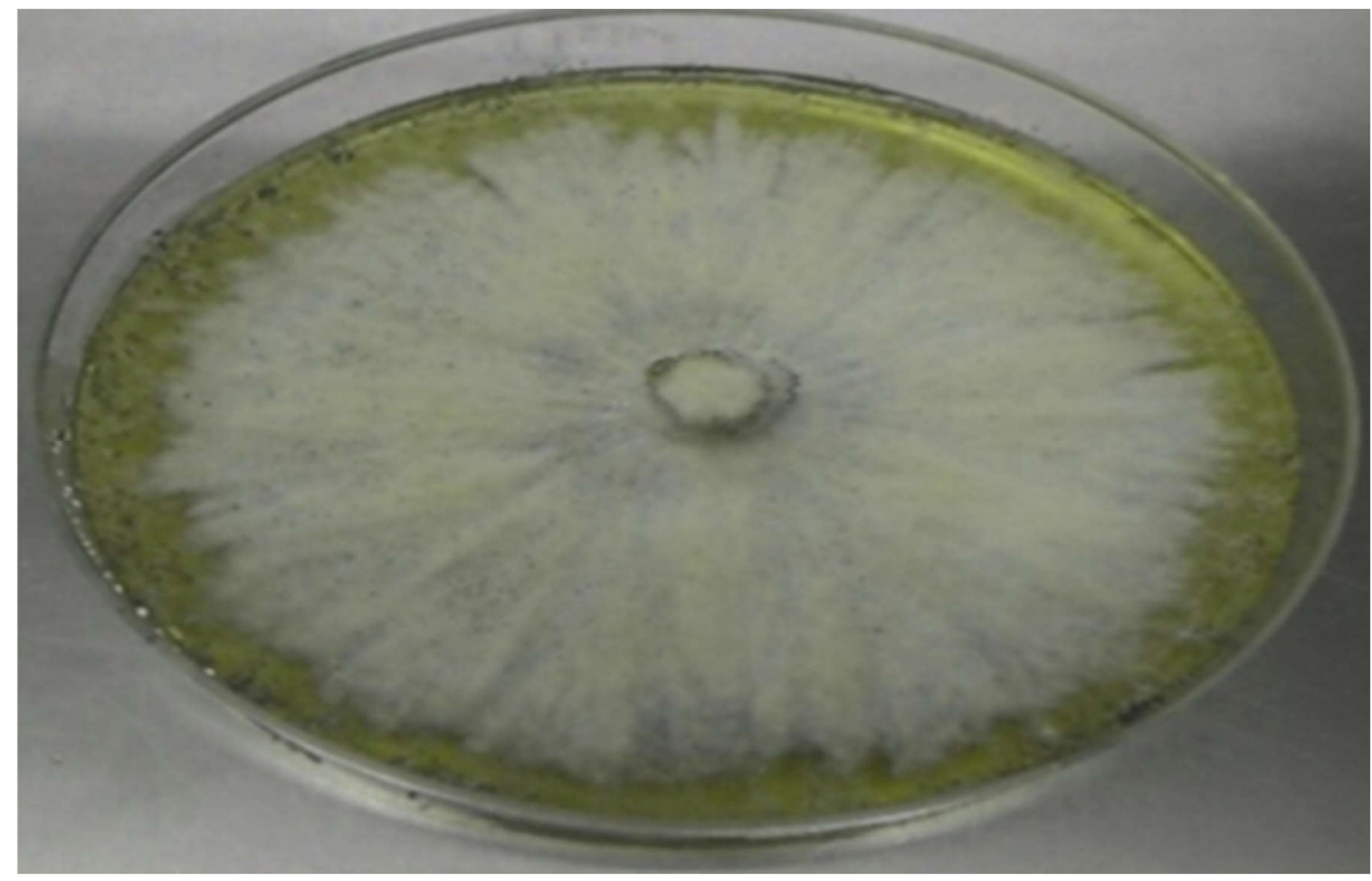

Fig. 1. Aspergillus elegans SweF9

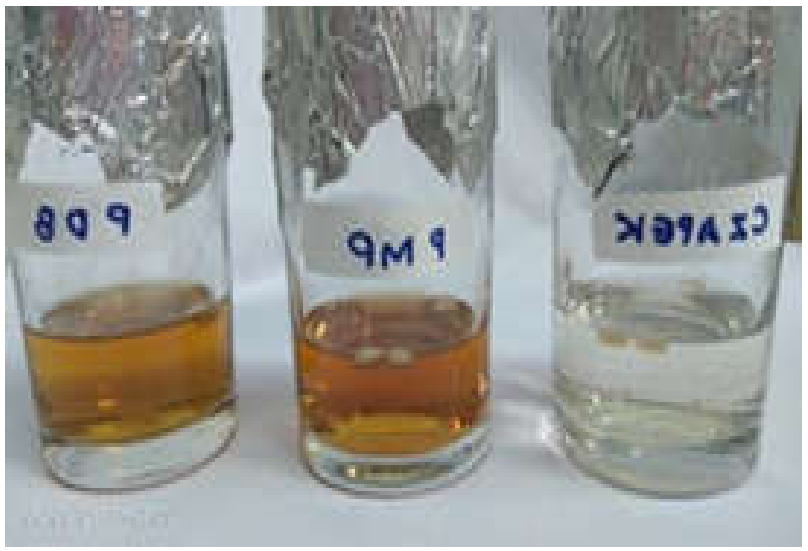

(a)

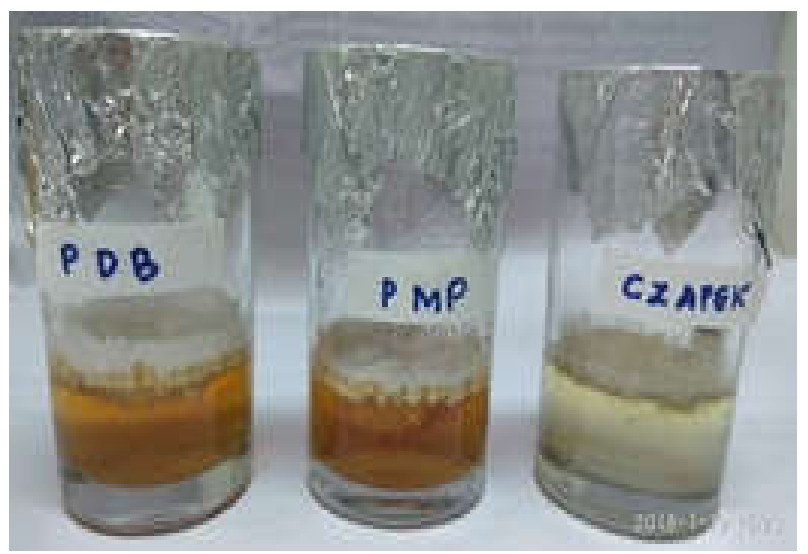

(b)

Fig. 2. Static liquid fermentation of A. elegans SweF9 at room temperature in media PDB, PMP and CDB (a) Day $0^{\text {th }} ;$ (b) Day $10^{\text {th }}$. 
After 10 days of incubation, each culture was harvested and separated between fungal biomass (B) and the filtrate (F).The biomass and filtrate obtained were extracted with ethyl acetate and dried with a rotary evaporator. Table 1 shows the weights of each extract of biomass and filtrate.

Table 1. The biomass and filtrate extract weight of A.elegans SweEP9 was cultivated in three types of liquid media

\begin{tabular}{llll}
\hline Media & Exstract & $\begin{array}{c}\text { biomass } \\
\text { weight } \\
\text { (gram) }\end{array}$ & $\begin{array}{c}\text { Extract } \\
\text { weight } \\
\text { (gram) }\end{array}$ \\
\hline PDB & B & 4.44 & 0.6542 \\
& F & - & 0.7878 \\
PMP & B & 4.39 & 0.7245 \\
& F & - & 0.8528 \\
CDB & B & 1.21 & 0.2768 \\
& F & - & 0.2169 \\
\hline
\end{tabular}

Notes: $B=$ biomass; $F=$ filtrate

Table 1 shows that the biomass weight and extract weight in the PDB and PMP media were relatively similar which indicates that the addition of nitrogen sources in the form of malt and peptone does not have much affect on the biomass weight and the metabolites produced by this fungus. Whereas in CDB medium, the biomass and extracts obtained were significantly less than PDB and PMP media. It was assumed that the medium CDB containing organic salts such as calcium phosphate as a buffer medium magnesium sulfate, potassium chloride, and Fesulfate were less suitable for A. elegans SweF9 biomass growth hence less extract weight was also obtained. Table 2 shows that the ethyl acetate extracts from biomass and filtrate of $A$. elegans SweF9 grown on 3 different liquid media were able to produce secondary metabolites that have an inhibitory activity to $\alpha$ glucosidase so that it has the potential to be developed as antidiabetic agents.

Table 2. $\alpha$-glucosidase inhibitory activity of extracts

\begin{tabular}{ccc}
\hline No & Sample name & IC $_{50}(\boldsymbol{\mu g} / \mathbf{m l})$ \\
\hline 1 & $\begin{array}{c}\text { Quercetin } \\
\text { (standard) }\end{array}$ & 1.38 \\
2 & PDB (B) & 15.96 \\
3 & PDB (F) & 1.74 \\
4 & PMP (B) & 38.20 \\
5 & PMP (F) & 5.49 \\
6 & CDB (B) & 147.01 \\
7 & CDB (F) & 81.45 \\
\hline
\end{tabular}

from biomass and filtrate of $A$. elegans SweF9

Notes: $B=$ biomass; $F=$ filtrate

Extract of the filtrate from the three types of media showed better inhibition of the $\alpha$ glucosidase than the biomass extract. This suggests that the active secondary metabolites that can inhibit the $\alpha$-glucosidase were more present in the filtrate (extracellular) than in biomass (intracellular). Filtrate extract from the PDB medium showed the best activity as an inhibitor of the $\alpha$-glucosidase ( IC $_{50} 1.74 \mu \mathrm{g} / \mathrm{mL}$ ) compared to other extracts. The PDB and PMP filtrate extract showed similar inhibitory activity, whereas the CDB extract showed significantly lower inhibitory activity, on biomass and filtrate extract. This differences can be caused by the influence of the content of secondary metabolites produced in each extract differently due to the influence of the composition of the media used. The order of activity of extracts in inhibiting $\alpha$ glucosidase is PDB (F)> PMP (F)> PDB (B)> $\mathrm{PMP}(\mathrm{B})>\mathrm{CDB}(\mathrm{F})>\mathrm{CDB}(\mathrm{B})$ respectively.

The results of this study differ from the antidiabetic activity of ethyl acetate extract of $A$. terreus MC751[11] and RCC1 [13]. A. terreus MC751[11] has the highest antidiabetic activity 
pp. 91 - 100, April 2020

when cultured in CDB media compared to PDP, PMP and malt extract media [11]. A. terreus RCC1 fungi extract which has the best antidiabetic activity on PMP media [13]. Although the media to produce the best antidiabetic activity of two different types of fungi in A. terreus MC751 and RCCI were different, the compound that has been successfully isolated is the same, namely butyrolactone I which has antidiabetic activity $[11,13]$. These results indicate that fungal species and media composition factors greatly influence on the secondary metabolites produced and secreted by fungi which has the $\alpha$ glucosidase inhibitory activity.

\subsection{HPLC profiling from biomass and filtrate ethyl acetate extracts}

To determine the effect of 3 different media compositions used in the profile of compounds produced by $A$. elegans Swe9, the biomass and filtrate extracts were analyzed using HPLC as shown in Figure 3. It appears that the HPLC profiles were relatively similar but has a different peak intensity.

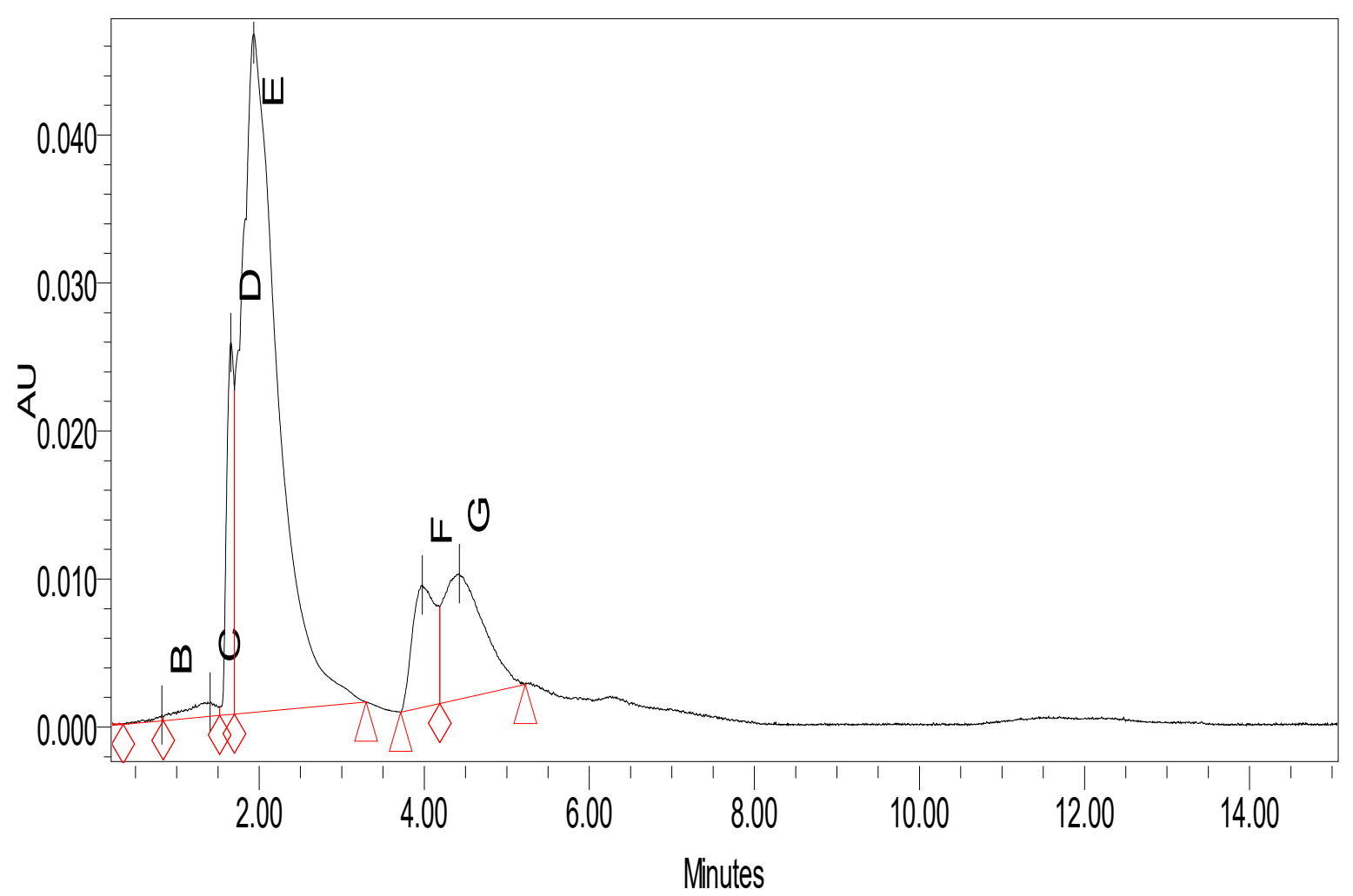

(i) HPLC chromatogram of PDB (B)

Fig. 3. HPLC chromatogram profiling of ethyl acetate extracts of A. elegans SweF9 biomass and filtrate. 
pp. 91 - 100, April 2020

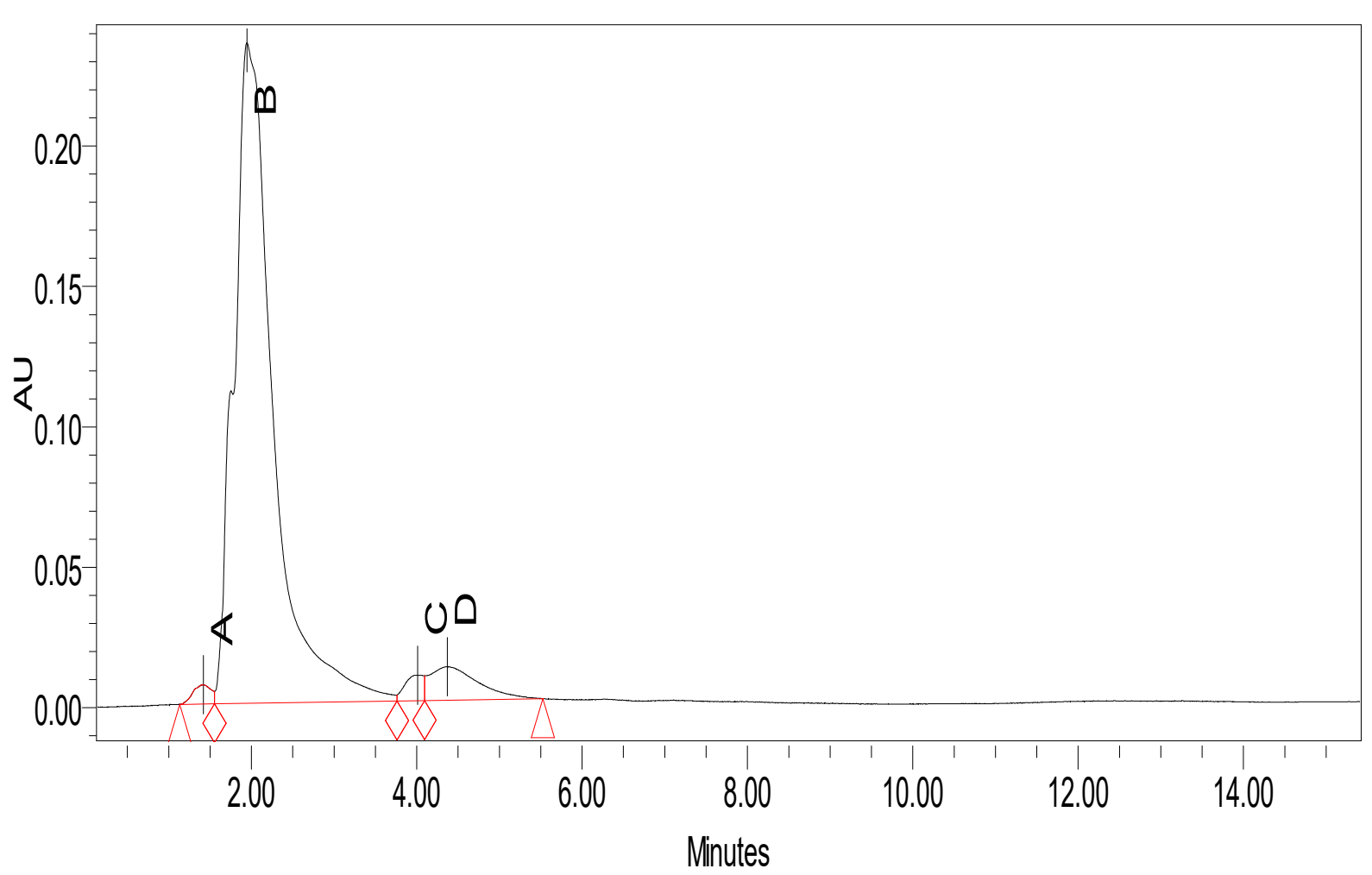

(ii) HPLC chromatogram of PDB (F)

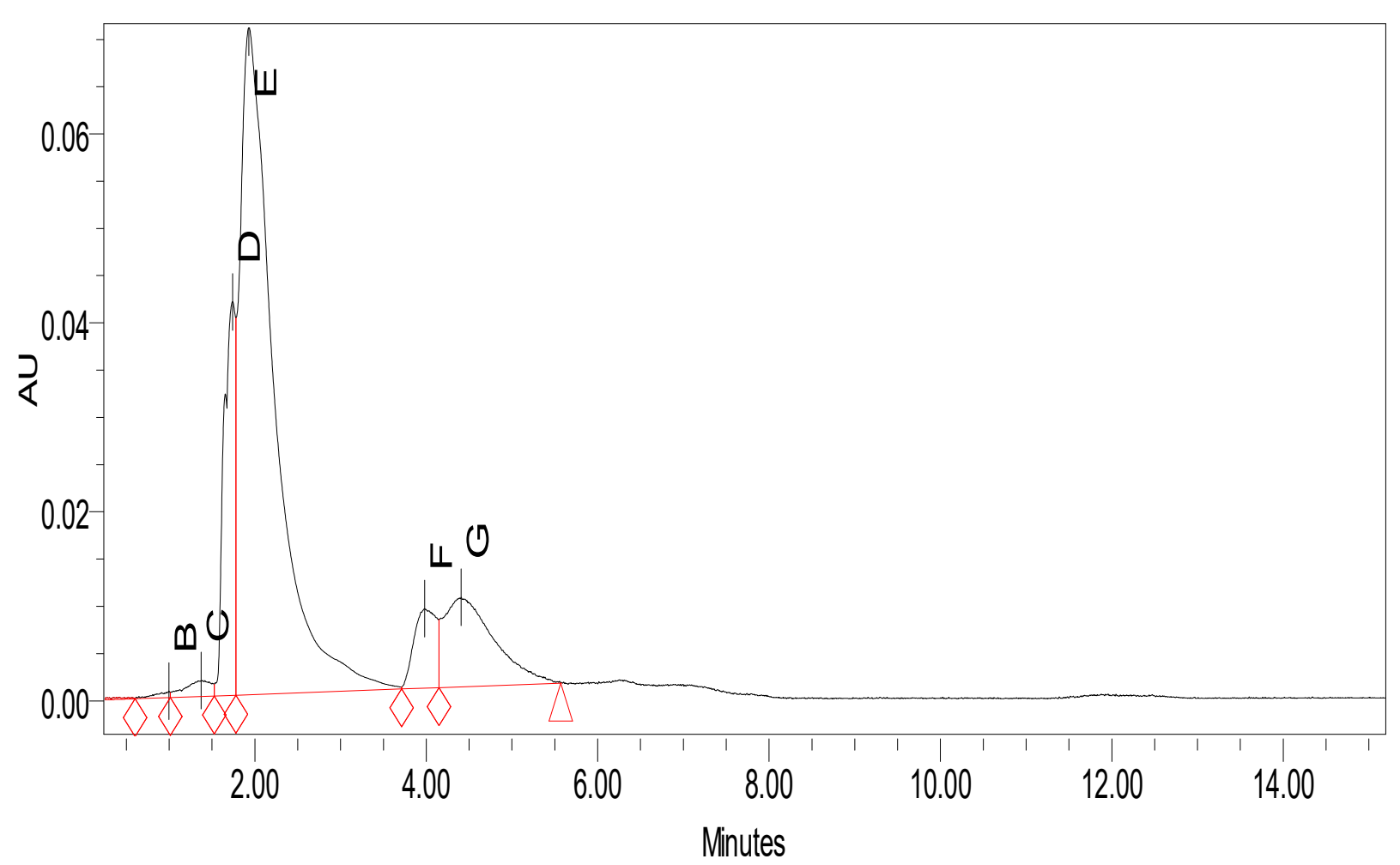

(iii) HPLC chromatogram of PMP (B)

Fig. 3 (continued). HPLC chromatogram profiling of ethyl acetate extracts of $A$. elegans SweF9 biomass and filtrate. 
pp. 91 - 100, April 2020

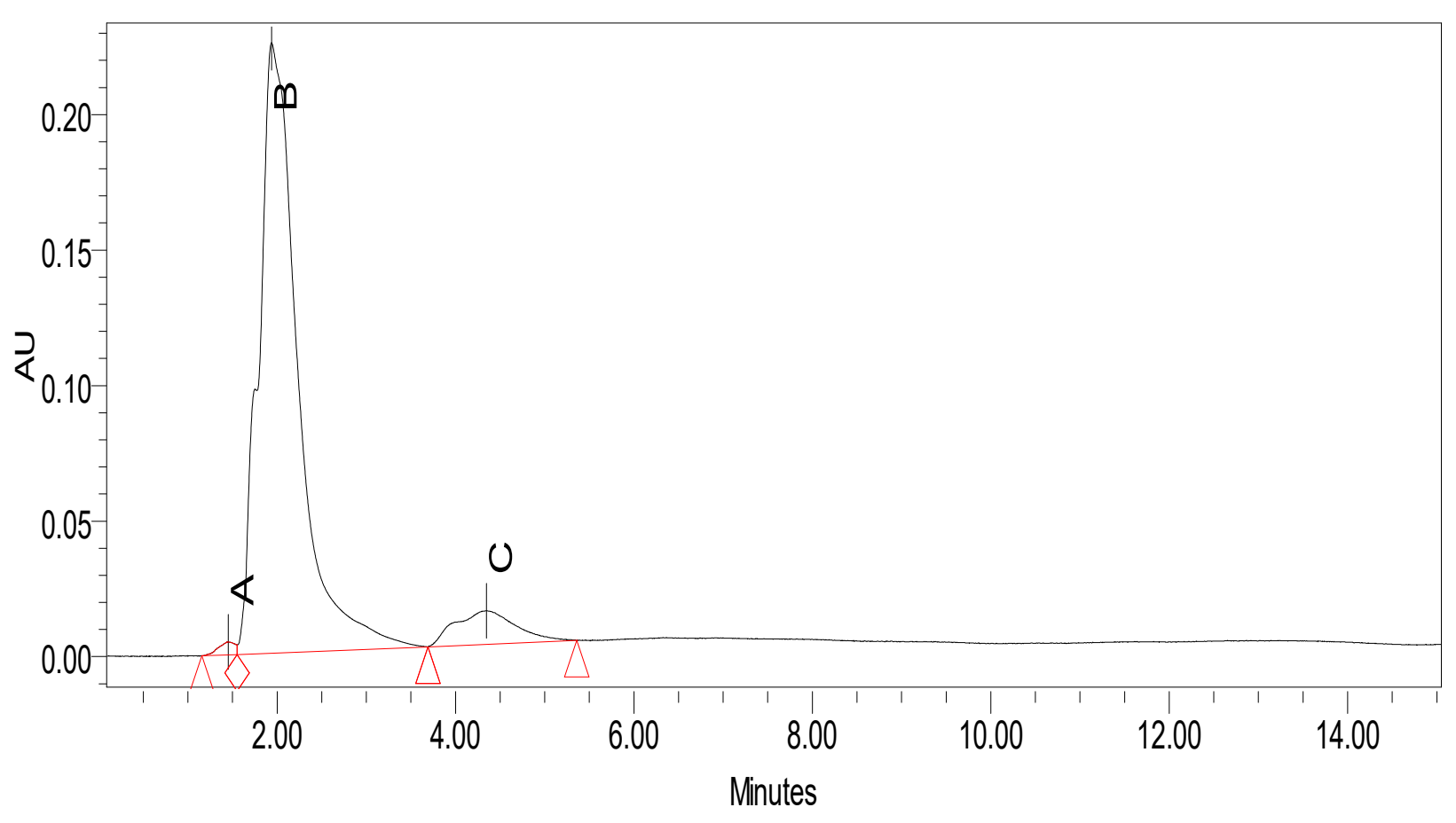

(iv) HPLC chromatogram of PMP (F)

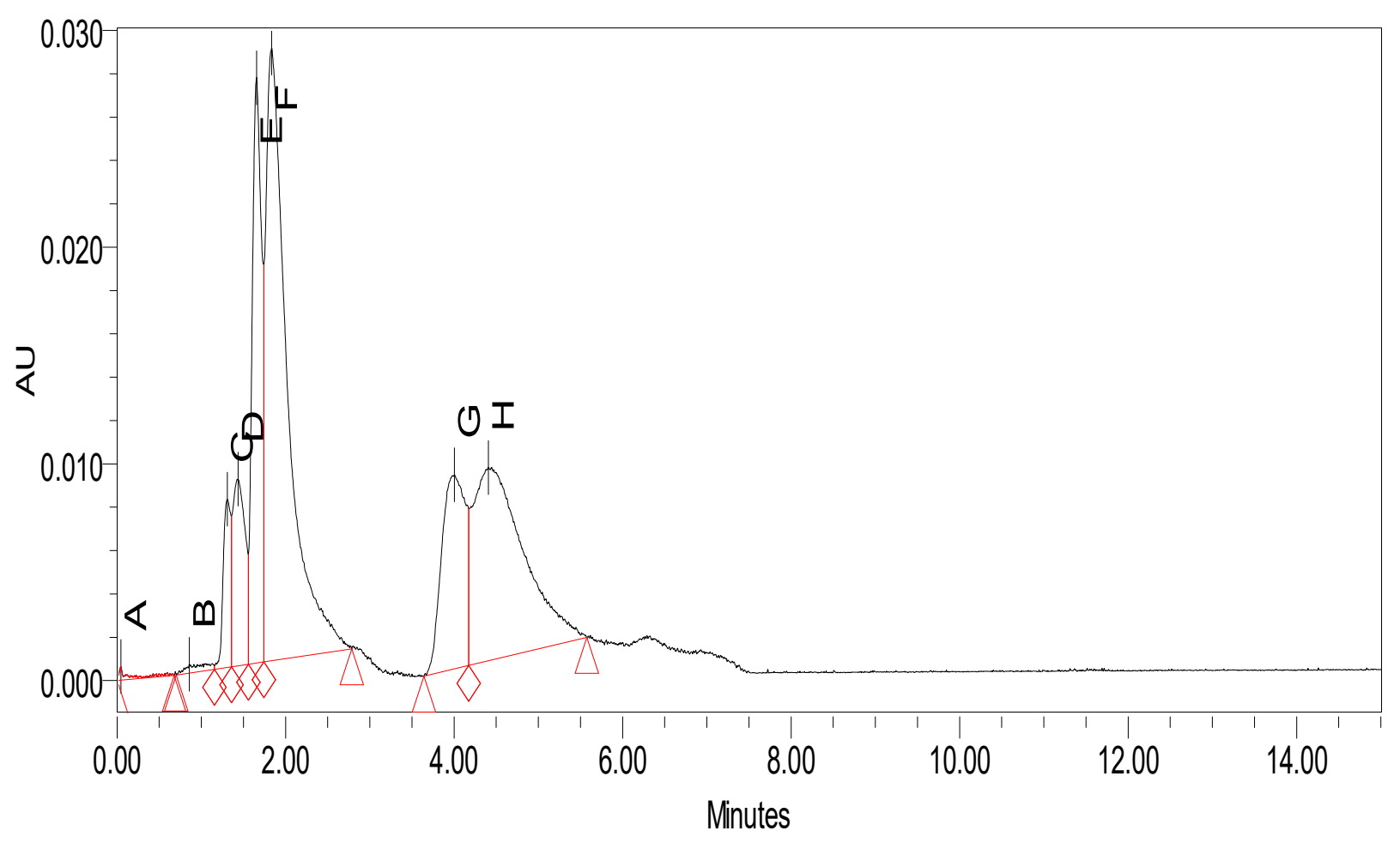

(v) HPLC chromatogram of CDB (B)

Fig. 3 (continued). HPLC chromatogram profiling of ethyl acetate extracts of $A$. elegans SweF9 biomass and filtrate.

98 | "Effect of Liquid Media Composition ...": Hani Mulyani, et.al. 


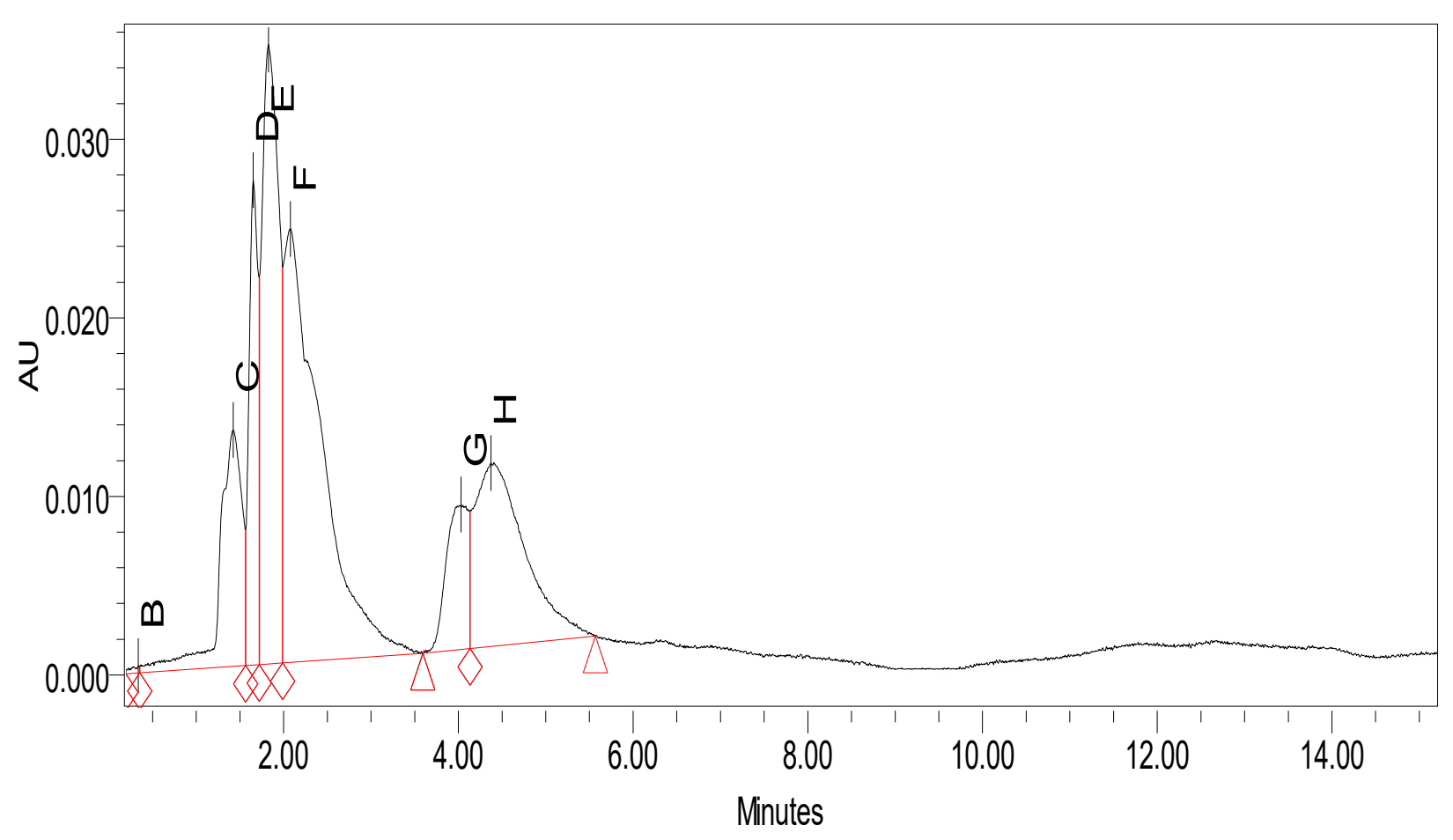

(vi) HPLC chromatogram of CDB (F)

Fig. 3 (continued). HPLC chromatogram profiling of ethyl acetate extracts of A. elegans SweF9 biomass and filtrate.

Table 3. Effect of media composition on antidiabetic activity and main peak from the HPLC analysis of $A$. elegans SweF9

\begin{tabular}{cccc}
\hline $\begin{array}{c}\text { Fermentation } \\
\text { media }\end{array}$ & $\begin{array}{c}\text { Antidiabetic } \\
\text { activity } \\
\text { rank }\end{array}$ & $\begin{array}{c}\text { Retention } \\
\text { time } \\
\text { (Peak) }\end{array}$ & $\begin{array}{c}\text { Area of } \\
\text { Main } \\
\text { Peak }\end{array}$ \\
\hline PDB (F) & 1 & 1.946 & 7723745 \\
PMP (F) & 2 & 1.938 & 6876414 \\
PDB (B) & 3 & 1.934 & 1998430 \\
PMP (B) & 4 & 1.930 & 1395375 \\
CDB (F) & 5 & - & - \\
CDB (B) & 6 & - & - \\
\hline
\end{tabular}

Notes: $\mathrm{B}=$ biomass; $\mathrm{F}=$ filtrate.

The results of the antidiabetic activity analysis can be correlated to HPLC results as shown in Table 3. HPLC chromatograms from
PDB and PMP media filtrate extracts which have higher antidiabetic activity have similar main peak with retention times of 1.946 and 1.938 while the area the peaks are 7,723,745 and $6,876,414$ respectively. Biomass extracts from PDP and PMP media have the same retention time but the peak area is much smaller which is in line with lower antidiabetic activity. Both filtrate and biomass extracts from CDB media which have significantly lower antidiabetic activities also showed different HPLC chromatogram pattern. These results are similar to the results of the analysis of HPLC A. terreus LS07, where ethyl acetate extract which has the best activity antidiabetes also has a high peak [13]. Further research is necessary to isolate the antidiabetic active compound from the fungus $A$. elegans SweF9. 


\section{CONCLUSION}

Based on the results of this study, Potato Dextrose Broth (PDB) is the most suitable medium for increasing the production of secondary metabolites that have $\alpha$-glucosidase inhibitory activity from endophytic fungus $A$. elegans SweF9. Accordingly, this fungus can be developed as a new source of antidiabetic. Further research is needed to isolate the antidiabetic compound from A. elegans SweF9.

\section{REFERENCES}

[1] A. Tahrani, and A. Barnett- Dafagliflozin: a sodium glucose cotransporter 2 inhibitor in development for type 2 diabetes. Diabetes ther, 1 (2), 45-46, 2010.

[2] L.H. Bösenberg, The mechanism of action of oral antidiabetic drugs: a review of recent literature. Metabolism and Diabetes of South Africa, The Journal of Endocrinology, vol. 13, pp. 80-88, 2008.

[3] P. Sudha, S.S. Zinjarde, S.Y. Bhargava and A.R. Kumar, Potent $\alpha$-amylase Inhibotory activity of Indian Ayurvedic Medicinal Plants. BMC Complementary and Alternative Medicine, vol. 11, pp. 2-5, 2011.

[4] C. Raghukumar, Marine fungal biotechnology: an ecological perspective. Fungal Divers. Vol. 31, pp. 19-35, 2008.

[5] S.A Balajee Aspergillus terreus complex. Medical Mycology. 2009. 47: 542-546.

[6] R.T Dewi, S. Tachibana S, and A. Darmawan. Antidiabetic and antioxidative activities of butyrolactone I from Aspergillus terreus MC751. World Academy, Science Engineering Technology. 2012. 70:882-887.

[7] Y. Srikandace and D.S.G. Andayani. Priliminary of Antibacterial Activity from Indonesia Marine-Derived Endophytic
Fungi. Adv Environ Biol. 9 (9), 143-149, 2015

[8] Y.M. Kim, M.H. Wang and H.I. Rhee, A novel $\alpha$-glucosidase inhibitor from pine bark. Carbohyd Res, vol. 339, pp. 715-717, 2004.

[9] R.T. Dewi, H. Mulyani, P.D.N Lotulung and N. Artanti, Evaluation of culture media for butyrolactone I production by Aspergillus tereus LSO7 As antidiabetic. Procedia Chemistry, vol.16, pp. $66-71$, 2015.

[10] R.T. Dewi, S. Tachibana and A. Darmawan, Effect on $\alpha$-glucosidase inhibition and antioxidant activities of butyrolactone derivatives from Aspergillus terreus MC751. Med Chem Res, vol.23, pp. 454-460, 2014.

[11] C.J. Zheng, C.L. Shao, L.Y. Wu, M. Chen, K.L. Wang, et al. Bioactive Phenylalanine Derivatives and Cytochalasins from the Soft Coral-Derived Fungus, Aspergillus elegans. Mar. Drugs. Vol. 11, pp. 20542068, 2013.

[12] R.T. Dewi, S. Tachibano, S. Fajriah, and M. Hanafi, $\alpha$-Glucosidase inhibitor compounds from Aspergillus terreus RCC1 and their antioxidant activity. Med Chem Res, vol. 24, pp. 737-743, 2015. 